\title{
Chemical Constituents, In Vitro Antioxidant Activity and In Silico Study on NADPH Oxidase of Allium sativum L. (Garlic) Essential Oil
}

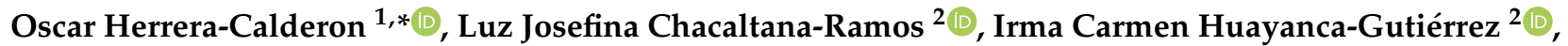 \\ Majed A. Algarni $\left.{ }^{3}{ }^{(}\right)$, Mohammed Alqarni ${ }^{4}\left(\mathbb{D}\right.$ and Gaber El-Saber Batiha ${ }^{5}$
}

1 Department of Pharmacology, Bromatology and Toxicology, Faculty of Pharmacy and Biochemistry, Universidad Nacional Mayor de San Marcos, Jr Puno 1002, Lima 15001, Peru

2 Department of Pharmaceutical Chemical, Faculty of Pharmacy and Biochemistry, Universidad Nacional San Luis Gonzaga, Av. Los Maestros s/n, Ica 11001, Peru; luz.chacaltana@unica.edu.pe (L.J.C.-R.); irma.huayanca@unica.edu.pe (I.C.H.-G.)

3 Department of Clinical Pharmacy, College of Pharmacy, Taif University, P.O. Box 11099, Taif 21944, Saudi Arabia; m.alqarni@tu.edu.sa

4 Department of Pharmaceutical Chemistry, College of Pharmacy, Taif University, P.O. Box 11099, Taif 21944, Saudi Arabia; m.aalqarni@tu.edu.sa

5 Department of Pharmacology and Therapeutics, Faculty of Veterinary Medicine, Damanhour University, Damanhour 22511, Egypt; dr_gaber_batiha@vetmed.dmu.edu.eg

check for

updates

Citation: Herrera-Calderon, O.; Chacaltana-Ramos, L.J;; Huayanca-Gutiérrez, I.C.; Algarni, M.A.; Alqarni, M.; Batiha, G.E.-S. Chemical Constituents, In Vitro Antioxidant Activity and In Silico Study on NADPH Oxidase of Allium sativum L. (Garlic) Essential Oil. Antioxidants 2021, 10, 1844. https:// doi.org/10.3390/antiox10111844

Academic Editors: Delia Mirela Tit and Simona Bungau

Received: 29 October 2021

Accepted: 18 November 2021

Published: 20 November 2021

Publisher's Note: MDPI stays neutral with regard to jurisdictional claims in published maps and institutional affiliations.

Copyright: (c) 2021 by the authors. Licensee MDPI, Basel, Switzerland. This article is an open access article distributed under the terms and conditions of the Creative Commons Attribution (CC BY) license (https:// creativecommons.org/licenses/by/ $4.0 /)$.
* Correspondence: oherreraca@unmsm.edu.pe; Tel.: +51-956-550-510

\begin{abstract}
Allium sativum L., also known as garlic, is a perennial plant widely used as a spice and also considered a medicinal herb since antiquity. The aim of this study was to determine by gas chromatography-mass spectrometry (GC-MS) the chemical profile fingerprint of the essential oil (EO) of one accession of Peruvian A. sativum (garlic), to evaluate its antioxidant activity and an insilico study on NADPH oxidase activity of the volatile phytoconstituents. The antioxidant activity was tested using DPPH and $\beta$-carotene assays. An in-silico study was carried out on NADPH oxidase (PDB ID: 2CDU), as was ADMET prediction. The results indicated that diallyl trisulfide $(44.21 \%)$ is the major component of the EO, followed by diallyl disulfide $(22.08 \%)$, allyl methyl trisulfide (9.72\%), 2-vinyl-4H-1,3-dithiine (4.78\%), and $\alpha$-bisabolol (3.32\%). Furthermore, the EO showed antioxidant activity against $\mathrm{DPPH}$ radical $\left(\mathrm{IC}_{50}=124.60 \pm 2.3 \mu \mathrm{g} / \mathrm{mL}\right)$ and $\beta$-carotene bleaching $\left(\mathrm{IC}_{50}=328.51 \pm 2.0\right.$ ). The best docking score on NADPH oxidase corresponds to $\alpha$ bisabolol $(\Delta \mathrm{G}=-10.62 \mathrm{kcal} / \mathrm{mol})$, followed by 5 -methyl-1,2,3,4-tetrathiane $(\Delta \mathrm{G}=-9.33 \mathrm{kcal} / \mathrm{mol})$. Additionally, the volatile components could be linked to the observed antioxidant activity, leading to potential inhibitors of NADPH oxidase.
\end{abstract}

Keywords: allyl compounds; molecular dynamic; antioxidant enzyme; oxidative stress; phytochemical study

\section{Introduction}

Essential oils (EOs) are natural products obtained from aromatic plants and can be extracted from leaves, roots, stems, flowers, and seeds, among others [1]. EOs are widely used in the food, cosmetic, alternative therapy (such as aromatherapy) and pharmaceuticals industries [2]. In terms of volatile chemical composition, EOs are mainly constituted by monoterpenes, sesquiterpenes, phenols, and alcohols. However, allyl structures and phenylpropanoids also constitute the phytochemical profile of some EOs [3]. EOs have been linked to antioxidant activity [4] as free radical scavengers and metal chelators [5], as well as to other biological activities such as anti-inflammatory, analgesic [6], sedative [7], antibacterial [8], antiviral [9], neuroprotective [10], and antifungal properties [11].

The generation of free radicals leads to oxidative stress in cells, which can trigger aging and degenerative diseases. The exposure to environmental stress, UV-radiation, viral 
and bacterial infection and carcinogenic chemicals, among other things, might also cause severe damage, brought about by the lipid peroxidation of polyunsaturated fatty acids and, consequently, the liberation of toxic metabolites [12]. Studies have revealed that essential oils inhibit lipid peroxidation in foods and in the biochemical process related to oxidative stress [2]. According to Amorati et al., the chemical fingerprint of EOs is mainly comprised of terpenoid and phenylpropanoid compounds [13]. Monoterpenes, free phenols, and allylic alcohols have all demonstrated potential antioxidant capacity in oxidative stress models, while other compounds grouped as sesquiterpenes, and non-isoprenoids have shown low antioxidant activity [14].

Nowadays, computational models such as molecular docking are carried out as a bioinformatic tool to study the inhibition of several enzymes that negatively affect the antioxidant activity, such as xanthine oxidase, nitric oxide synthases (NOS), cytochrome P450 reductase, and nicotinamide-adenine dinucleotide phosphate (NADPH) oxidase, as well as the mitochondrial electron transport chain. Furthermore, it is known that reactive oxygen species (ROS) generation occurs in the mitochondria via oxidative phosphorylation and through the enzyme NADPH oxidase [15]. Additionally, NADPH oxidase-mediated cell proliferation participates in intracellular signaling processes and has been observed in a variety of cancer cells and in tissue repair processes [16]. Thus, the screening of inhibitory molecules on this target could be useful to ameliorate numerous chronical or degenerative diseases and to find selective and non-toxic inhibitors of NADPH oxidases, providing new drugs for the treatment of diseases related to oxidative stress-dependent processes [17].

Allium satioum L. (family Amaryllidaceae), also known as garlic is widespread across the world, being used mainly in gastronomy and for its medicinal properties. Within its medical uses, several pharmacological activities have been evaluated, such as its potential anticancer, hypotensive, hepatoprotective, hypoglycemic, antimicrobial, and immunomodulatory effects [18]. Garlic essential oil contains sulfur compounds as the main volatile phytochemicals, dominated by allyl polysulfides, such as diallyl disulfide, diallyl trisulfide, and diallyl disulfide. Different methods to obtain EOs adopted in some studies which might affect the chemical composition due to enzymatic biotransformation processes occurring during the extraction process, i.e., hydrodistillation compared to the microwave-assisted extraction method $[19,20]$. The type of apparatus used during the extraction could also influence the results, i.e., use of a Clevenger apparatus vs. industrial extraction. Considering the role of the edaphic factor on the plant growth and chemical composition of different metabolites of interest, the chemical profile of essential oils has been shown to be affected by all these factors [21]. Altitude also plays an important role; to date only the results for garlic collected in low altitudes ranging between 500 and 1000 m.a.s.l. have been reported [22]. Additionally, remarkable qualitative and quantitative differences have been found in EOs extracted after following different drying procedures [23]. In Peru, garlic is used mainly as a food additive, and according to National Institute of Agrarian Innovation (INIA-PERU), Peru has several accessions of garlic such as Purple, Criollo or Napurí, Barranquino, Massone, Pata de Perro, and White Chinese [24], with White Chinese being one of the most consumed and commercialized accessions.

To date, some accounts of the antioxidant capacity of garlic EOs determined by different methods have been reported. However, those garlic samples were cultivated at low altitudes and their chemical compositions could differ to those of garlic cultivated in high altitude zones. In-silico studies allow one to identify molecules with promising inhibitory effects on any antioxidant target such as NADPH oxidase, which is considered an important antioxidant marker in biological systems. The focus on antioxidant phytochemicals contained in EOs is directly linked to their application for the prevention of oxidative damage caused by ROS. Hence, low-molecular antioxidants such as allyl polysulfide structures enhance organism stability under conditions of oxidative stress. Based on all these antecedents, the aims of this research were: (1) To determine the phytochemical constituents of garlic EO by gas chromatography-mass spectrometry (GC-MS) and their antioxidant activity against the 1,1-diphenyl-2-picrylhydrazyl (DPPH) radical and $\beta$-carotene 
bleaching; (2) to evaluate in-silico the inhibitory effect of the volatile phytochemicals of the essential oil from A. sativum L. (garlic) on NADPH oxidase (PDB ID: 2CDU).

\section{Materials and Methods}

\subsection{Chemicals}

All analytical grade (99.5\%) solvents (dichloromethane, chloroform, methanol) and hydrogen peroxide were purchased from Merck (Darmstadt, Germany). 2,2-Diphenyl-1picrylhydrazyl (DPPH), $\beta$-carotene, linoleic acid, Trolox, and rutin were purchased from Sigma Aldrich (St Louis, MO, USA).

\subsection{Plant Material}

A quantity of $800 \mathrm{~g}$ of $A$. sativum (bulbs) cultivated in the Arequipa region of Peru (2.335 m.a.s.l.), was used to carry out the experimental procedures. Bulbs were cleaned and peeled before being placed in a Clevenger equipment to obtain the essential oil by hydrodistillation for $2 \mathrm{~h}$ [25]. The essential oil was separated by decantation, then anhydrous $\mathrm{Na}_{2} \mathrm{SO}_{4}$ was added to eliminate any remaining water drops. Finally, the EO was stored in a sealed amber vial until further use.

\subsection{Identification of Volatile Compounds by Gas Chromatography-Mass Spectrometry (GC-MS)}

Volatile chemicals were determined with a GC-MS system (7890 Gas Detector and 5975C Mass Spectrometer Detector, Agilent Technologies, Santa Clara, CA, USA). Then, $0.0136 \mathrm{~g}$ of the sample was weighed and mixed with $0.5 \mathrm{~mL}$ of dichloromethane. Next, $1.0 \mu \mathrm{L}$ of the working solution was injected into the equipment in splitless mode (split ratio: 20:1). The EO was run on a J\&W 122-1545.67659 DB-5ms column $(60 \mathrm{~m} \times 250 \mu \mathrm{m} \times 0.25 \mu \mathrm{m}$, Agilent Technologies). The working conditions were as follows: the temperature program started at $40{ }^{\circ} \mathrm{C}$, with increments of $5{ }^{\circ} \mathrm{C} / \mathrm{min}$ up to $180{ }^{\circ} \mathrm{C}$, followed by increases of $2.5^{\circ} \mathrm{C} / \mathrm{min}$ up to $200^{\circ} \mathrm{C}$ for $5 \mathrm{~min}$ and finally $10^{\circ} \mathrm{C} / \mathrm{min}$ up to $300^{\circ} \mathrm{C}$, followed by holding for $3 \mathrm{~min}$. The helium flow rate was at $1 \mathrm{~mL} / \mathrm{min}$. Volatile chemicals were identified and confirmed by comparing the mass spectrum of the compounds with the NIST20 library data [26].

\subsection{Antioxidant Activity}

\subsubsection{2,2-Diphenyl-1-picrylhydrazyl (DPPH) Assay}

The 2,2-diphenyl-1-picrylhydrazyl (DPPH) method according to Rojas-Armas et al. [27] with slight modifications, was used as an organic radical activity assay. For $0.1 \mathrm{mM}$ of the DPPH solution, methanol was used as a solvent, and $100 \mu \mathrm{L}$ of this solution was mixed with $900 \mu \mathrm{L}$ of EO at different concentrations $(0-1000 \mu \mathrm{g} / \mathrm{mL})$. Then, the reaction tubes were incubated at room temperature for $30 \mathrm{~min}$ and protected from light. Finally, the absorbance was measured at $517 \mathrm{~nm}$ using a Genesys 20 spectrophotometer (Thermo Scientific, Waltham, MA, USA). Trolox was used as an antioxidant control. The inhibitory concentration $\left(\mathrm{IC}_{50}\right)$ was calculated from the plot of inhibition percentage against the sample concentration.

\subsection{2. $\beta$-Carotene Bleaching Assay}

The lipid peroxidation activity was determined by the $\beta$-carotene bleaching method according to Tepe et al. [28]. A stock solution containing $0.5 \mathrm{mg}$ of $\beta$-carotene in $1 \mathrm{~mL}$ of chloroform was then mixed with $200 \mathrm{mg}$ of Tween 40 and $25 \mu \mathrm{L}$ of linoleic acid. Then, the chloroform was removed under vacuum at $40{ }^{\circ} \mathrm{C}$ for 5 min using a R-100 ${ }^{\circledR}$ rotary evaporator (Buchi, Flawil, Switzerland). Subsequently, $100 \mathrm{~mL}$ of $3 \%$ aqueous hydrogen peroxide solution was added to the residue and mixed for 5 min until an emulsion was obtained. Then, aliquots $(2.5 \mathrm{~mL})$ of the emulsion were mixed with garlic $\mathrm{EO}(350 \mu \mathrm{L})$ and rutin. All test tubes were incubated at $25^{\circ} \mathrm{C}$ up to $48 \mathrm{~h}$ and read at $490 \mathrm{~nm}$ using a Genesys 20 spectrophotometer. 
2.5. Molecular Docking of the Phytochemical Volatiles of Garlic on the Receptor NADPH Oxidase (PDB ID: 2CDU)

Prior to the docking study, 13 volatile oil compounds of Allium sativum (garlic) were drawn in ChemDraw 19.0 (Perkin Elmer, Waltham, MA, USA), and subsequently, the geometry was optimized. The receptor NADPH oxidase was retrieved from the protein data bank (PDB ID: 2CDU). Before performing molecular interaction studies, NADPH oxidase was further curated for missing side-chain residues using the openMM tool. Molecular docking studies were performed with Autodock v 4.2.6 (The Scripps Research Institute, La Jolla, CA, USA). The binding cavity for ligand compound docking in NADPH oxidase was determined from the predefined co-crystallized X-ray structure from RCSB PDB. The residue positions were calculated within $3 \AA$ from the co-crystallized ligand. After the cavity selection in each case, the co-crystallized ligands were removed using the Chimera tool (https: / / www.cgl.ucsf.edu/chimera /, accessed on 11 September 2021), and subsequently, the energy was minimized using the steepest descent and conjugate gradient algorithm. Then, finally, merging the nonpolar hydrogens, both the receptor and target compound were saved in pdbqt format. A grid box was created with parameters $X=68$, $\mathrm{Y}=58$, and $\mathrm{Z}=64 \AA$ with $0.3 \AA$ spacing. Following the Lamarckian genetic algorithm (LGA), docking studies of the protein-ligand complex were performed to achieve the lowest free energy of binding $(\Delta G)$. During the molecular docking studies, three replicates were performed, with a total number of 50 solutions computed in each case, with a population size of 500, a number of evaluations of 2,500,000, a maximum number of generations of 27,000 , and rest the default parameters were allowed. After docking, the RMSD clustering maps were obtained by the re-clustering command with a clustering tolerance of $0.25,0.5$, and $1 \AA$, respectively, in order to obtain the best cluster with the lowest energy score and a high number of populations.

\subsection{Molecular Dynamic (MD) Studies}

The MD simulation studies were carried on the best docked complexes for NADPH oxidase with $\alpha$-bisabolol and standard diallyl trisulfide using Desmond 2020.1 from Schrödinger, LLC (New York, NY, USA). The OPLS-2005 force field and explicit solvent model with the SPC water molecules were used in this system. $\mathrm{Na}+$ ions were added to neutralize the charge. Moreover, $0.15 \mathrm{M}$, of the $\mathrm{NaCl}$ solution was added to the system to simulate the physiological environment. The NPT ensemble was set up using the Nose-Hoover chain coupling scheme with a temperature of $27^{\circ} \mathrm{C}$, a relaxation time of $1.0 \mathrm{ps}$, and a pressure of $1 \mathrm{bar}$, maintained in all of the simulations. A time step of $2 \mathrm{fs}$ was used. The Martyna-Tuckerman-Klein chain coupling scheme barostat method was used for pressure control with a relaxation time of 2 ps. The particle mesh Ewald method was used for calculating long-range electrostatic interactions, and the radius for the coulomb interactions were fixed at $9 \AA$. The RESPA integrator was used for a time step of 2 fs for each trajectory calculating the bonded forces. The root means square deviation (RMSD), radius of gyration $(\mathrm{Rg})$, root mean square fluctuation (RMSF), and number of hydrogen (H-bonds) were calculated to monitor the stability of the MD simulations [29].

\subsection{ADMET Prediction}

The absorption, distribution, metabolism, excretion, and toxicity (ADMET) properties of the compounds determined in the essential oil of garlic were calculated using the pkCSM online tool (http:/ / biosig.unimelb.edu.au/pkcsm/prediction, accessed on 21 October 2021) [30] and SwissADME (http:/ / www.swissadme.ch/, accessed on 21 October 2021) [31].

\subsection{Statistical Analysis}

The preparation of essential oil was carried out three times, and the mean and SD of the three independent experiments are presented. The antioxidant assays were repeated three times. The statistical tools employed were Student's $t$-test, two-tailed, and the $\mathrm{IC}_{50}$ values 
were estimated by linear regression statistics. $p$-Values less than 0.05 were considered statistically significant. GraphPad Prism program version 6.0 (GraphPad Software, La Jolla, CA, USA) was used to develop the statistical analysis.

\section{Results and Discussion}

\subsection{Chemical Profile of the Essential Oil of A. sativum}

The obtained EO showed a pale yellow color, an extraction yield of $0.78 \%$ (v/dry weight), and a density of $0.95 \pm 0.01 \mathrm{~g} / \mathrm{mL}$ at $20^{\circ} \mathrm{C}$. The volatile components of garlic essential oil were analyzed by GC-MS and are presented in Table 1 . According to our results, we identified 17 compounds, four of which are of unknown structures, which accounted for $100 \%$ of the total composition. The analysis identified diallyl trisulfide (retention time $24.97 \mathrm{~min}$ ) as the main component $(44.21 \%$ ) of the volatile chemicals, followed by diallyl disulfide (22.08\%), allyl methyl trisulfide (9.72\%), and 2-vinyl-4H-1,3-dithiine (4.78\%). According to Figure S1 of the Supplementary Materials, the total time for the evaluation was $50 \mathrm{~min}$.

Table 1. Chemical composition of the volatile oil of A. sativum (garlic).

\begin{tabular}{|c|c|c|c|c|c|}
\hline $\mathbf{N}^{\circ}$ & $\begin{array}{l}\text { Compound Name } \\
\text { (NIST08.L) }\end{array}$ & $\underset{(\min )}{\mathrm{Rt}}$ & $\begin{array}{c}\text { Molecular } \\
\text { Formula/ } \\
\text { Molecular Mass }\end{array}$ & $\begin{array}{c}\% \text { In Sample } \\
\text { (Relative Areas) }\end{array}$ & Chemical Structure \\
\hline 1 & Allyl methyl disulfide & 12.75 & $\begin{array}{l}\mathrm{C}_{4} \mathrm{H}_{8} \mathrm{~S}_{2} \\
(120.36)\end{array}$ & $0.47 \pm 0.01$ & \\
\hline 2 & 3H-1,2-Dithiole & 14.18 & $\begin{array}{l}\mathrm{C}_{3} \mathrm{H}_{4} \mathrm{~S}_{2} \\
(104.19)\end{array}$ & $2.41 \pm 0.02$ & \\
\hline 3 & Diallyl disulfide & 18.11 & $\begin{array}{c}\mathrm{C}_{6} \mathrm{H}_{10} \mathrm{~S}_{2} \\
(146.3)\end{array}$ & $22.08 \pm 0.11$ & \\
\hline 4 & $\begin{array}{c}\text { 1-Propenyl } \\
\text { 2-propenyl- }(E) \text {-disulfide }\end{array}$ & 18.69 & $\begin{array}{l}\mathrm{C}_{6} \mathrm{H}_{10} \mathrm{~S}_{2} \\
(146.27)\end{array}$ & $0.92 \pm 0.01$ & \\
\hline 5 & Allyl methyl trisulfide & 20.06 & $\begin{array}{l}\mathrm{C}_{4} \mathrm{H}_{8} \mathrm{~S}_{3} \\
(152.29)\end{array}$ & $9.72 \pm 0.05$ & \\
\hline 6 & Unknown & 20.92 & $\begin{array}{l}\mathrm{C}_{6} \mathrm{H}_{10} \mathrm{~S}_{2} \\
(146.27)\end{array}$ & $1.08 \pm 0.01$ & n.d. \\
\hline 7 & $\begin{array}{c}\text { 3-Vinyl-1,2- } \\
\text { dithiacyclohex-4-ene }\end{array}$ & 21.71 & $\begin{array}{l}\mathrm{C}_{6} \mathrm{H}_{8} \mathrm{~S}_{2} \\
(144.25)\end{array}$ & $2.56 \pm 0.01$ & \\
\hline 8 & 4H-1,2,3-Trithiine & 22.18 & $\begin{array}{l}\mathrm{C}_{3} \mathrm{H}_{4} \mathrm{~S}_{3} \\
(136.25)\end{array}$ & $3.07 \pm 0.01$ & \\
\hline 9 & 2-Vinyl-4H-1,3-dithiine & 22.46 & $\begin{array}{l}\mathrm{C}_{6} \mathrm{H}_{8} \mathrm{~S}_{2} \\
(144.25)\end{array}$ & $4.78 \pm 0.01$ & \\
\hline 10 & Unknown & 24.66 & $\begin{array}{l}\mathrm{C}_{9} \mathrm{H}_{16} \mathrm{O}_{2} \mathrm{~S} \\
(188.29)\end{array}$ & $0.50 \pm 0.01$ & \\
\hline 11 & Diallyl trisulfide & 24.97 & $\begin{array}{c}\mathrm{C}_{6} \mathrm{H}_{10} \mathrm{~S}_{3} \\
(178.33)\end{array}$ & $44.21 \pm 0.08$ & \\
\hline
\end{tabular}


Table 1. Cont.

\begin{tabular}{|c|c|c|c|c|c|}
\hline $\mathbf{N}^{\circ}$ & $\begin{array}{l}\text { Compound Name } \\
\text { (NIST08.L) }\end{array}$ & $\begin{array}{c}\mathrm{Rt} \\
(\mathrm{min})\end{array}$ & $\begin{array}{c}\text { Molecular } \\
\text { Formula/ } \\
\text { Molecular Mass }\end{array}$ & $\begin{array}{c}\% \text { In Sample } \\
\text { (Relative Areas) }\end{array}$ & Chemical Structure \\
\hline 12 & 1-Allyl-3-propyltrisulfane & 25.22 & $\begin{array}{c}\mathrm{C}_{6} \mathrm{H}_{12} \mathrm{~S}_{3} \\
(180.34)\end{array}$ & $1.37 \pm 0.01$ & \\
\hline 13 & $\begin{array}{l}\text { 5-Methyl-1,2,3,4- } \\
\text { tetrathiane }\end{array}$ & 27.20 & $\begin{array}{l}\mathrm{C}_{3} \mathrm{H}_{6} \mathrm{~S}_{4} \\
(170.32)\end{array}$ & $1.55 \pm 0.01$ & \\
\hline 14 & Unknown & 31.50 & $\begin{array}{l}\mathrm{C}_{9} \mathrm{H}_{16} \mathrm{~S}_{3} \\
(220.42)\end{array}$ & $0.85 \pm 0.01$ & n.d. \\
\hline 15 & Diallyl tetrasulfide & 31.55 & $\begin{array}{l}\mathrm{C}_{6} \mathrm{H}_{10} \mathrm{~S}_{4} \\
(210.39)\end{array}$ & $0.68 \pm 0.01$ & \\
\hline 16 & $\alpha$-Bisabolol & 35.42 & $\begin{array}{l}\mathrm{C}_{15} \mathrm{H}_{26} \mathrm{O} \\
(222.37)\end{array}$ & $3.32 \pm 0.03$ & \\
\hline 17 & Unknown & 45.26 & $\begin{array}{c}\mathrm{C}_{22} \mathrm{H}_{42} \mathrm{O}_{4} \\
(370.57)\end{array}$ & $0.43 \pm 0.01$ & n.d. \\
\hline
\end{tabular}

Rt, retention time; n.d., not determined.

Regarding the phytochemical analysis of garlic essential oil by GC-MS, our results differ to those of other investigations and could be explained by the different extraction methods used to obtain the EO, such as conventional or non-conventional techniques. For example, in sono-hydrodistillation and ultrasound-assisted hydrodistillation, the obtained garlic essential oil has, as a major component, diallyl disulfide, whilst is lower in hydrodistillation [32]. In our study, the most representative molecule was diallyl trisulfide, with $44.21 \%$, followed by diallyl sulfide, with $22.08 \%$. However, in recent studies, as reported by Thuy et al., allyl disulfide was the main component, with $28.44 \%$ [9]. In an analysis of garlic EO from Cameroon, diallyl trisulfide $(41.62 \%)$ and diallyl disulfide $(19.74 \%)$ were the major components [33]. In a Tunisian study, allyl disulfide (28.0\%) and eugenol (15.37\%) were the most abundant constituents [34]. In Saudi Arabia, the major component was allyl methyl trisulfide, with $13.10 \%$. [35]. Garlics from Thailand showed values of diallyl disulfide, diallyl trisulfide, and diallyl tetrasulfide, equivalent to $31.67 \%, 31.56 \%$, and $13.48 \%$, respectively [36]. On the contrary, the drying procedure also affects the composition of sulfur components, i.e., garlic EO from Tunisia obtained by freeze drying contained $45.9 \%$ diallyl trisulfide compared to $42.3 \%$ for an oven-dried extract and $37.3 \%$ for an air-dried extract [37]. The diversity of the chemical composition in garlic EO might be related with external factors such as temperature, soil composition, climate conditions, environmental stress, ecosystem, and altitude. Arequipa is situated at 2335 m.a.s.l., which could be an advantage to produce an EO with a phytochemical profile different to other varieties of garlic found across the world [38]. 


\subsection{Antioxidant Profile of A. sativum Essential Oil}

Garlic EO exhibited strong antioxidant activity, as shown in Table 2. Trolox showed better antioxidant activity than the EO. On the contrary, there was a significant difference between EO and Trolox concentrations $(p=0.0002)$. The EO of $A$. sativum showed a good antioxidant response, but other research has reported different values; for example, according to Lawrence et al., the EO of garlic grown in the north Indian plains showed an $\mathrm{IC}_{50}$ value of $0.5 \mathrm{mg} / \mathrm{mL}$ [39]. Another $\mathrm{IC}_{50}$ value that has been reported is $7.67 \mathrm{mg} / \mathrm{mL}$, for an oil obtained by hydrodistillation [40]. In our study the EO showed an $\mathrm{IC}_{50}$ of $124.60 \pm 2.5 \mu \mathrm{g} / \mathrm{mL}$, which is different to the findings of Ndoye et al. [33], with an IC $\mathrm{C}_{50}$ value of $0.19 \mu \mathrm{g} / \mathrm{mL}$. This is a high value compared to the other results, which could be due to the presence of diallyl trisulfide, diallyl disulfide, and methylallyl di- and trisulfides. Although diallyl sulfide was the main component of the garlic EO produced by hydrodistillation, dialyl disulfide and allyl methyl sulfide did not demonstrate any antioxidant action when tested as inhibitors of the controlled autoxidation of isopropylbenzene or styrene, implying that they are oxidized together with the oxidizable substrate [13]. We detected diallyl trisulfide as the major compound, whilst other sulfur volatiles have been shown to be abundant in other garlic EOs. However, some techniques to extract essential oil might affect its antioxidant activity, according to Boubechiche et al. [32]. The EO obtained by hydrodistillation had a better antioxidant capacity $\left(\mathrm{IC}_{50}=0.96 \mathrm{mg} / \mathrm{mL}\right)$ than that obtained using the ultrasound-assisted $\left(\mathrm{IC}_{50}=1.176 \mathrm{mg} / \mathrm{mL}\right)$ and sono-hydrodistillation processes $\left(\mathrm{IC}_{50}=1.234 \mathrm{mg} / \mathrm{mL}\right)$. After microwave-assisted extraction, the EO showed an inhibition percentage of $72.06 \%$ at $500 \mu \mathrm{g} / \mathrm{mL}$ [41]. Factors such as altitude, climate conditions, and chemotype varieties may also be responsible for the differences observed in our study [42]. Regarding the $\beta$-carotene bleaching assay, there was a significant difference between rutin and the garlic EO $(p=0.0012)$, being the antioxidant standard more than garlic EO. In a recent study by Ncir et al. [34], an $\mathrm{IC}_{50}$ value of $\beta$-carotene equivalent to $0.2 \pm 0.02 \mathrm{mg} / \mathrm{mL}$ was reported, similar to our results but contrary to the DPPH assay, with an $\mathrm{IC}_{50}$ value of $0.048 \pm 0.007 \mathrm{mg} / \mathrm{mL}$.

Table 2. Antioxidant activities of the A. sativum essential oil.

\begin{tabular}{ccc}
\hline \multirow{2}{*}{ Samples } & \multicolumn{2}{c}{ Antioxidant Activity } \\
\cline { 2 - 3 } & DPPH & $\beta$-Carotene \\
& IC $_{\mathbf{5 0}}(\boldsymbol{\mu g} / \mathrm{mL})$ & IC $_{\mathbf{5 0}}(\boldsymbol{\mu g} / \mathrm{mL})$ \\
\hline Essential oil of Allium sativum & $124.60 \pm 2.3^{* *}$ & $328.51 \pm 2.0^{*}$ \\
Trolox & $0.54 \pm 0.02$ & - \\
Rutin & - & $3.5 \pm 0.05$ \\
\hline
\end{tabular}

Values are reported as the mean \pm SD of three experiments. ${ }^{*} p<0.01 ;{ }^{* *} p<0.001$. Student's $t$-test, two-tailed.

Another factor considered was the presence of $\alpha$-bisabolol, which has not been found in other garlic EOs and which could influence the antioxidant activity, as shown in Table 2 in comparison to other garlic EOs from across the world.

\subsection{Molecular Docking of the Phytochemical Constituents of the Essential Oil from A. sativum}

Molecular docking studies were carried out in order to understand the interaction profile of various volatile oil compounds present in A. sativum with NADPH oxidase. Out of the 13 specific compounds found abundant in the chromatography results, $\alpha$ bisabolol displayed lowest the binding energy, with $(\Delta G)-10.62 \mathrm{kcal} / \mathrm{mol}$ and a predicted inhibitory concentration (Ki) of $0.14 \mu \mathrm{M}$ (Table 3). The principal residues of NADPH oxidase LYS187 and TYR188 were involved in conventional polar hydrogen bond formation with $\alpha$-bisabolol (Figure 1). On the contrary, 5-methyl-1,2,3,4-tetrathiane and 4H-1,2,3-trithiine also displayed better binding with NADPH oxidase, followed by $\alpha$-bisabolol, with $\Delta \mathrm{G}$ -9.33 and $-9.05 \mathrm{kcal} / \mathrm{mol}$, respectively (Table 1 ). However, the predicted $\mathrm{Ki}$ was observed to be 1.24 and $1.90 \mu \mathrm{M}$, respectively (Table 1). The common residue of NADPH oxidase CYS133 was involved in both the cases, forming polar hydrogen bonds (Figure 1), while 
other than CYS133, GLY244 also indulged in forming conventional hydrogen bonds with 5-methyl-1,2,3,4-tetrathiane (Figure 1). All of the other ligands' interaction profiles are presented in Table 3 and Supplementary Materials Figures S2-S10.

The inhibition of NADPH oxidase in silico by sulfur components and alpha-bisabolol could be correlated with the in vitro results presented by Schepetkin et al., including the garlic EO and three compounds (diallyl trisulfide, ajoene, and allicin), which inhibited the neutrophil ROS production, with diallyl trisulfide being the major component attributed to ROS inhibition [43]. Additionally, S-allylcysteine showed antioxidant activity, inhibiting gp91 ${ }^{\text {phox }}$ and gp22 $2^{\text {phox }}$ of NADPH oxidase, where gp91phox was the catalytic subunit and gp22 $2^{\text {phox }}$ is a membrane protein, both of which formed a complex generating superoxide radical, and its over-activation has been linked to several renal diseases [44].

Table 3. Ligand interaction energies and inhibitory concentrations with NADPH oxidase in the molecular docking study.

\begin{tabular}{ccccc}
\hline No. & Ligand Name & $\Delta \mathbf{G}(\mathbf{k c a l} / \mathbf{m o l})$ & $\mathbf{K i}(\boldsymbol{\mu M})$ & Residues Involved in Polar Bonds \\
\hline 1 & Allyl methyl disulfide & -6.85 & 15.0 & VAL214 \\
2 & 3H-1,2-Dithiole & -7.45 & 5.45 & CYS133 \\
3 & Diallyl disulfide & -7.19 & 8.48 & ILE243, GLY244 \\
4 & 1-Propenyl 2-propenyl-(E)-disulfide & -6.59 & 23.2 & LYS187 \\
5 & Allyl methyl trisulfide & -6.65 & 21.1 & MET33 \\
6 & 3-Vinyl-1,2-dithiacyclohex-4-ene & -8.87 & 2.78 & VAL81 \\
7 & CH-1,2,3-Trithiine & -9.05 & 1.90 & VAL8133 \\
8 & 2-Vinyl-4H-1,3-dithiine & -7.69 & 3.64 & GLY244 \\
9 & Diallyl trisulfide & -7.36 & 6.37 & GLY244 \\
10 & 1-Allyl-3-propyltrisulfan & -7.76 & 3.32 & CYS133, GLY244 \\
11 & 5-Methyl-1,2,3,4-tetrathiane & -9.33 & 1.24 & - \\
12 & Diallyl tetrasulfide & -6.21 & 44.4 & LYS187, TYR188 \\
\hline
\end{tabular}

VAL, valine; CYS, cysteine; ILE, isoleucine; GLY, glycine; LYS, lysine; MET, methionine; TYR, tyrosine.

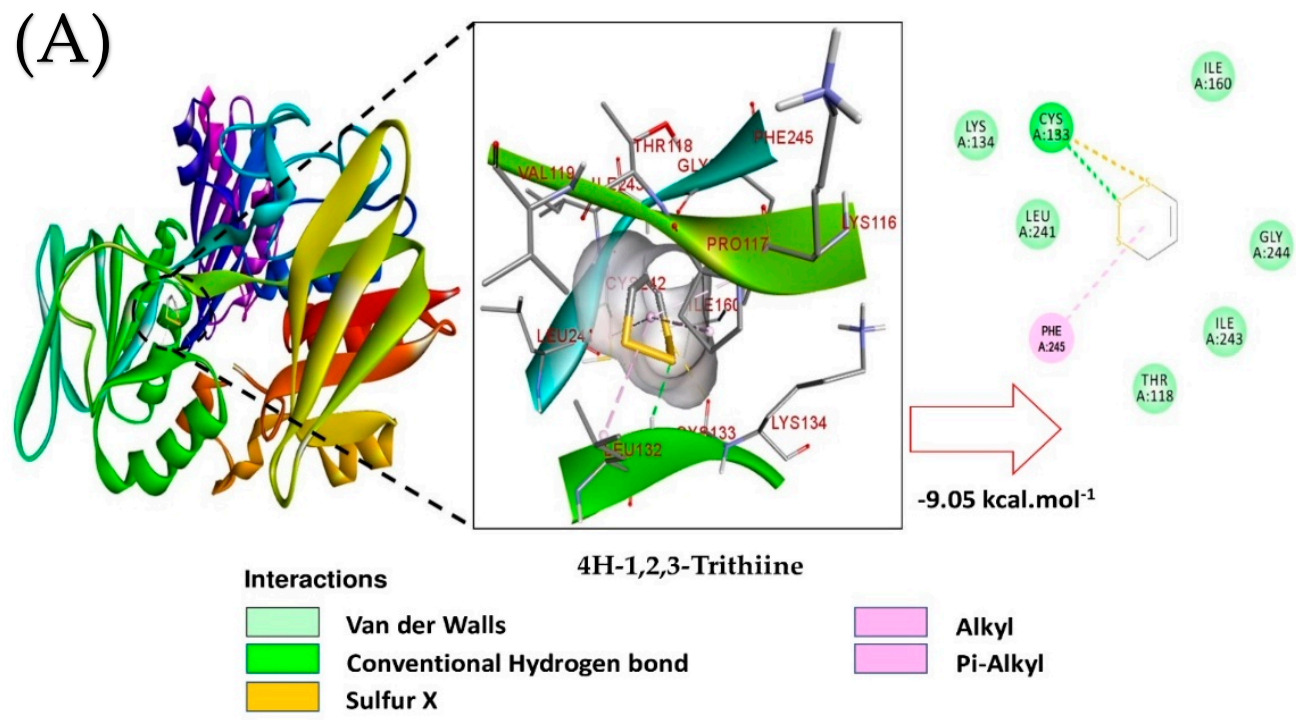

Figure 1. Cont. 

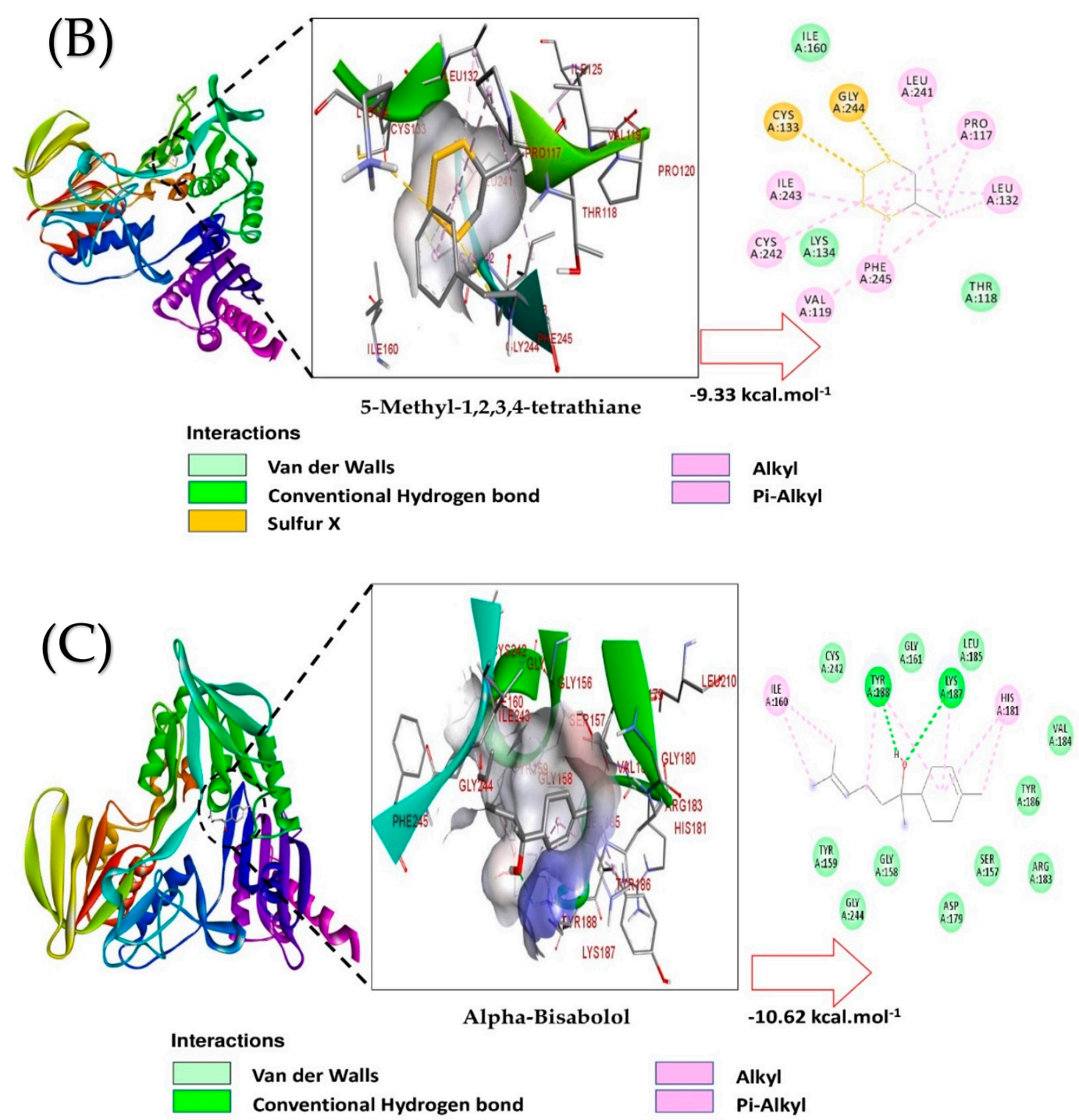

Figure 1. Molecular interaction studies of the most active phytochemical constituents of garlic essential oil with NADPH oxidase (PDB ID: 2CDU). (A): 4H-1,2,3-trithiine, (B): 5-methyl-1,2,3,4-tetrathiane, and (C): $\alpha$-bisabolol. Surface view (left panel), and 2D (right panel) interactions.

\subsection{Molecular Dynamics of the Phytoconstituents of the Essential Oil from A. sativum}

In molecular dynamics, the two most common parameters of structural fluctuations are the root mean square deviation (RMSD) and the root mean square fluctuations (RMSF). The RMSD measures the average displacement of the atoms at an instant of the simulation relative to a reference structure, generally the first frame of the crystallographic structure or simulation. The RMSF measures the displacement of a particular atom, or group of atoms, relative to the reference structure, averaged over the number of atoms. The RMSD is useful for analysis of time-dependent motions of a structure. It is frequently used to discern whether a structure is stable during the time-scale of the simulations [45].

Molecular dynamics studies of NADPH oxidase with $\alpha$-bisabolol and diallyl trisulfide were carried out for a $100 \mathrm{~ns}$ simulation time scale. A total of $100 \mathrm{~ns}$ of simulation time analysis of the trajectories displayed convergence of the root mean square deviation (RMSD) for $\alpha$-bisabolol with an average deviation $0.1 \AA$ (Figure 1A, dark cyan). Meanwhile, with diallyl trisulfide, the RMSD showed little more fluctuation compared to alpha-bisabolol, with an average deviation $0.5 \AA$ (Figure 2A, orange). RMSD deviations of the bound complexes were exhibited within an acceptable range, and with alpha-bisabolol, the $\mathrm{C} \alpha$ of NADPH oxidase was more stable. The RMSF of individual amino residues of NADPH 
oxidase over the function of a $100 \mathrm{~ns}$ time scale displayed low fluctuations in $\alpha$-bisabolol, with an average of $0.1 \AA$ (Figure 2B, drak cyan). Low fluctuations of the amino acid residues indicate higher stability from a converged structure. However, amino acid residues of NADPH oxidase bound to diallyl trisulfide fluctuated more at positions 70 and 370, respectively, as compared to the $\alpha$-bisabolol-bound complex (Figure 2B, orange).

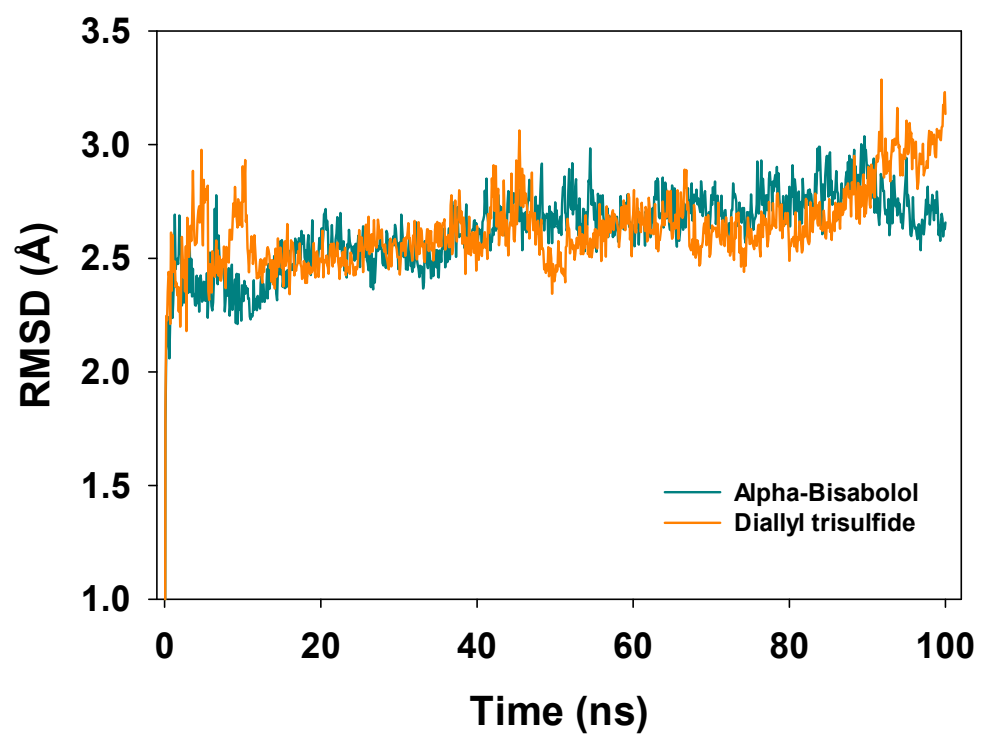

(A)

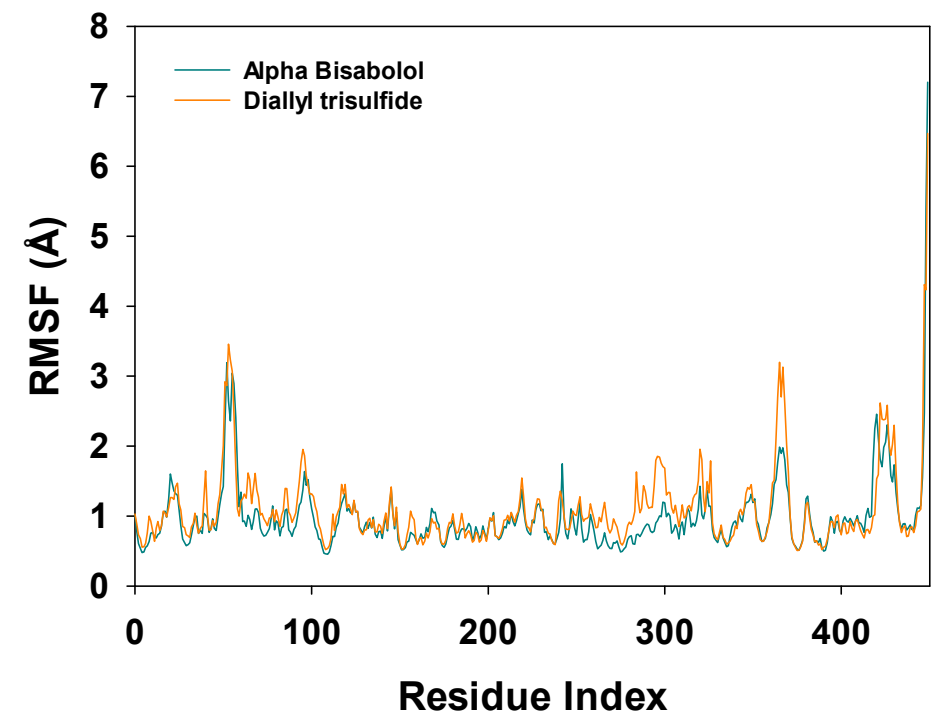

(B)

Figure 2. (A) RMSD plot of $\mathrm{C} \alpha$ atoms of NADPH oxidase displaying deviations from the mean with $\alpha$-bisabolol (dark cyan) and diallyl trisulfide (orange) over a 100 ns time scale simulation. (B) RMSF plot of amino acids of NADPH oxidase bound to $\alpha$-bisabolol (dark cyan) and diallyl trisulfide (orange) over a $100 \mathrm{~ns}$ time scale simulation.

The radius of gyration is the measure of compactness of the protein in the ligandbound state. The MD simulation of $100 \mathrm{~ns}$ of NADPH oxidase $\mathrm{C} \alpha$ atoms complexed with $\alpha$-bisabolol displayed a slight lowering of the trajectory due to compactness of the complex (Figure 3A, dark cyan); meanwhile, the complex with diallyl trisulfide (orange) displayed more fluctuations and a less compact structure compared to the $\alpha$-bisabolol-bound complex (Figure 3A, orange). 


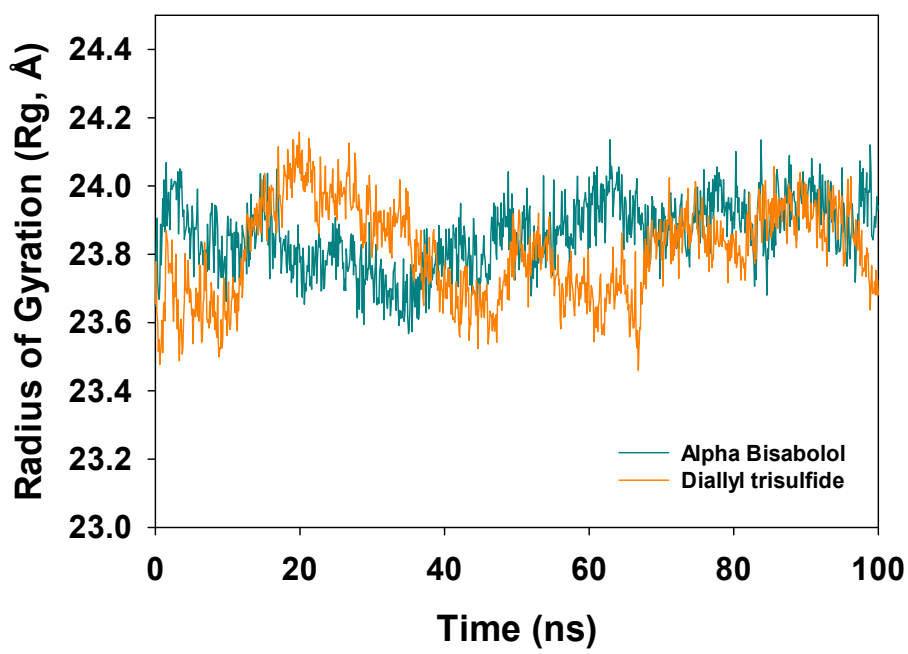

(A)

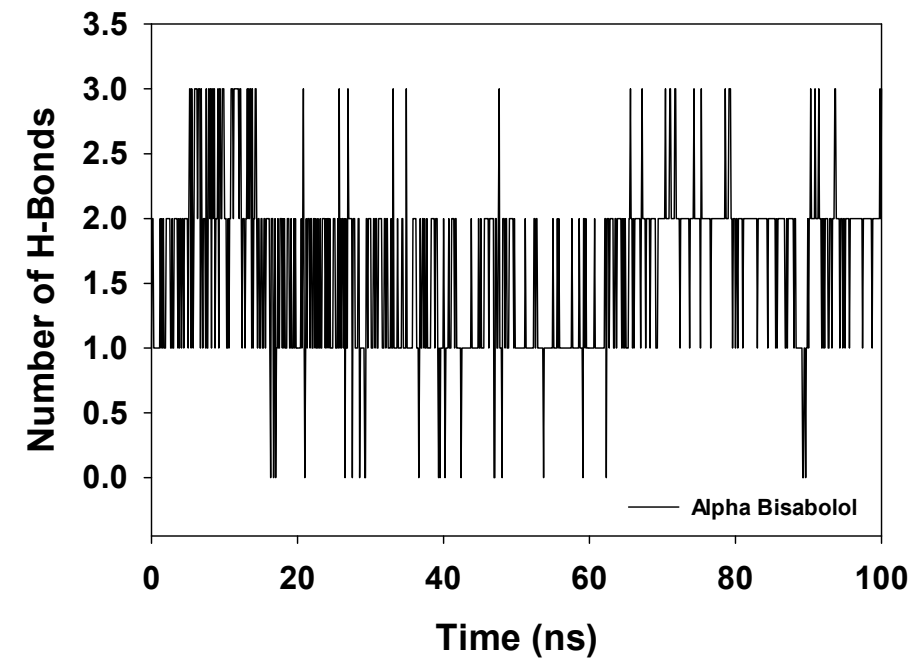

(B)

Figure 3. (A) Radius of gyration (Rg) plot of $\mathrm{C} \alpha$ atoms of NADPH oxidase complexed with $\alpha$ bisabolol (dark cyan) and diallyl trisulfide (orange). (B) Number of hydrogen bonds formed between NADPH oxidase and $\alpha$-bisabolol throughout a simulation time of $100 \mathrm{~ns}$.

The number of hydrogen bonds formed between proteins and ligands is an important factor when analyzing a stable complex throughout a simulation. Here, in this case, the number of H-bonds formed between NADPH oxidase and $\alpha$-bisabolol displayed a consistent interaction, with an average of 1.5 throughout the $100 \mathrm{~ns}$ simulation (Figure $2 \mathrm{~B}$ ). In contrast, with diallyl trisulfide, no hydrogen bond formations were recorded. The total energy of the system is another essential function to draw a conclusion regarding the stability of a complex. NADPH oxidase- $\alpha$-bisabolol displayed an average of $-35 \mathrm{kcal} / \mathrm{mol}$, where most of the energies were favorably contributed by the non-bonded Coulomb and van der Waal's forces (vdW) interactions of -5 and $-25 \mathrm{kcal} / \mathrm{mol}$, respectively (Figure $4 \mathrm{~A}$ ). On the contrary, the diallyl trisulfide-bound NADPH oxidase complex displayed an average energy of $-27 \mathrm{kcal} / \mathrm{mol}$, where the vdW energy contributed more favorably than the Coulomb energy (Figure 4B). The comparative energy plots indicate a more stable and converged structure of $\alpha$-bisabolol-bound NADPH oxidase than the standard diallyl trisulfide. Therefore, from the simulation studies, it can be suggested that $\alpha$-bisabolol has the potential to be a better inhibitor against NADPH oxidase and can substitute the application of diallyl trisulfide. 


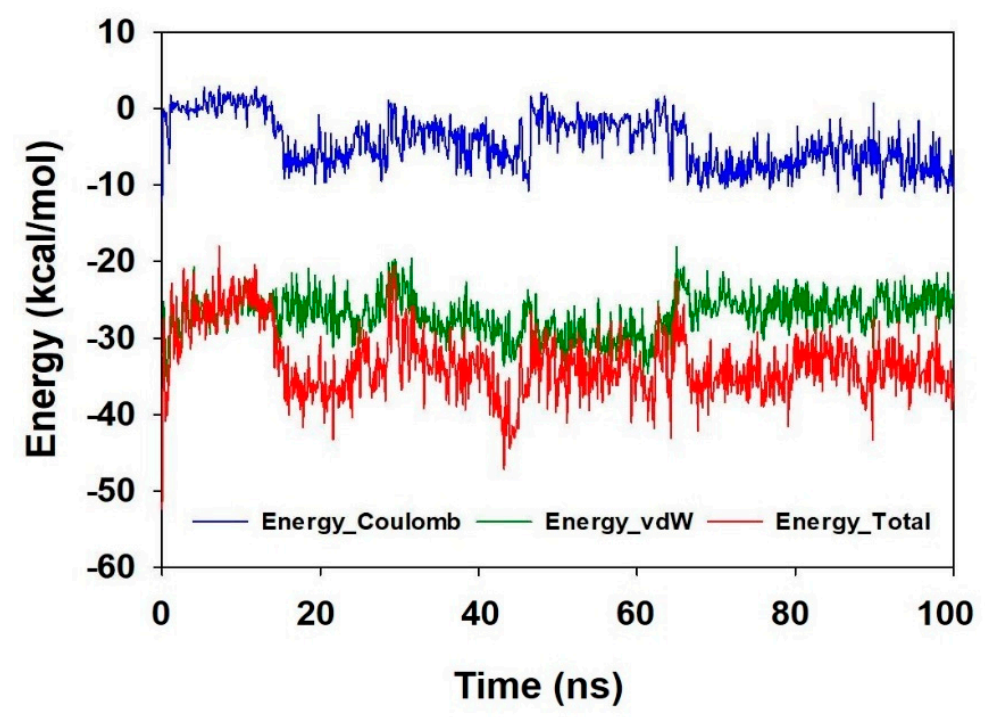

(A)

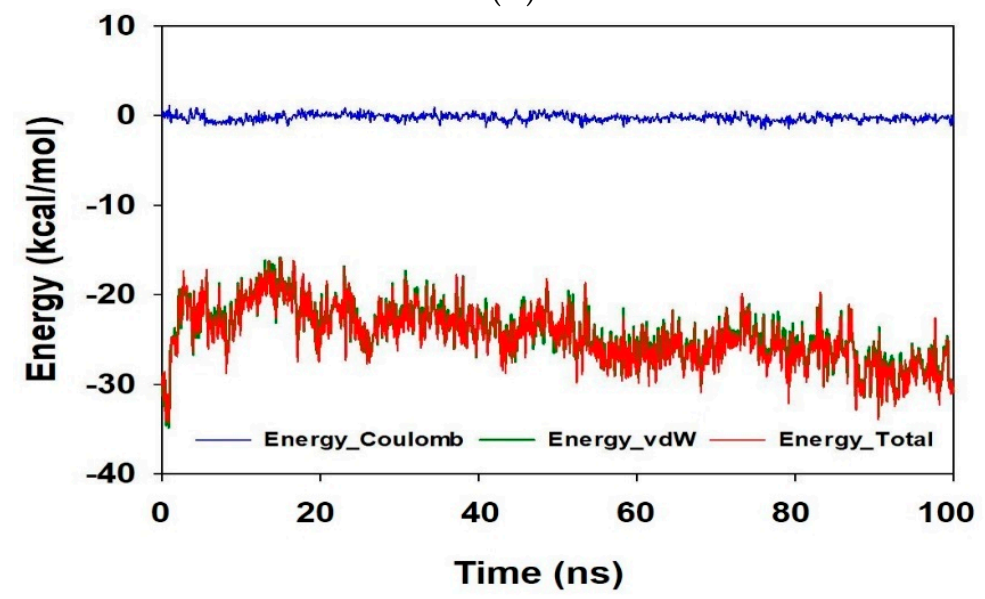

(B)

Figure 4. Energy plots of NADPH oxidase complexed with (A) $\alpha$-bisabolol and (B) diallyl trisulfide.

\subsection{ADMET Profiles}

The chemical constituents of the garlic essential oil were analyzed using the online pkCSM tool to predict the absorption, distribution, metabolism, excretion, and toxicity profiles. The results revealed that all compounds had a molecular weight ranging between 100 and $400 \mathrm{~g} / \mathrm{mol}$, which is important for penetrability, because the profile to achieve this parameter is for those compounds with values less than $500 \mathrm{~g} / \mathrm{mol}$. The Caco-2 permeability had values above 0.90 and a high intestinal absorption (90-95\%), which would predict that all compounds of the garlic EO will be absorbed in the small intestine [29]. Due to the lipophilic character of chemical components in garlic EOs, they tend to form micelles and are digested in the small intestine [46]. The skin permeability ranged from -1.29 to $-2.232 \mathrm{~cm} / \mathrm{h}(\leq 2.5)$, which means that volatile phytochemicals easily penetrate the skin.

The volume distribution (VDss) is acceptable due to its values above -0.15 . On the contrary, 11 compounds are probably able to penetrate the blood-brain barrier (BBB) $(\log \mathrm{BB}>0.3)$, but 3H-1,2-dithiole and 3-vinyl-1,2-dithiacyclohex-4-ene had a medium value under 0.3 , which would result in difficultly accessing the brain. The central nervous system (CNS) permeability achieved between -2.644 and -1.649; therefore, only 5-methyl$1,2,3,4$-tetrathiane is able to permeate the central nervous system $(\log \mathrm{P}>-2)$, as values $\log \mathrm{P}<-3$ are unable to penetrate it. Table 4 shows that all of constituents are not able to interfere with CYP2D6 and CYP3A4 and would not be metabolized by either. The excretion parameters showed that the total clearance $(0.103$ and $1.363 \log \mathrm{mL} / \mathrm{min} / \mathrm{kg})$ 
achieved positive values, meaning a quick excretion [15]. Volatile organic compounds can influence the expression and activity of cytochrome P450 enzymes and transferases involved in the metabolism of other drugs in the system. Additionally, drug interactions of essential oil components should be considered if any medication is used together with EOs. Furthermore, all compounds showed no potential contraindication, because they are not substrates of the organic cation transport 2 (OCT2), which is involved in the uptake and secretion of cationic drugs. Regarding the toxicity, the acute oral toxicity in rats $\left(\mathrm{LD}_{50}\right)$ ranged from 1.739 to $3.035 \mathrm{~mol} / \mathrm{kg}$, meaning a low toxicity. Additionally, they were not considered hepatotoxic substances (Table 4).

Table 4. ADMET properties of the chemical constituents of the A. sativum essential oil (in the metabolism analysis for CYP 2D6 inhibitors, CYP 3A4 inhibitors, renal OCT2 substrate, and hepatotoxicity, no data were obtained).

\begin{tabular}{|c|c|c|c|c|c|c|c|c|c|}
\hline \multirow[b]{2}{*}{$\mathbf{N}^{\circ}$} & \multicolumn{3}{|c|}{ Absorption } & \multicolumn{3}{|c|}{ Distribution } & \multirow{2}{*}{$\begin{array}{c}\text { Excretion } \\
\text { Total } \\
\text { Clearance } \\
\text { (Log } \\
\text { mL/min/kg) }\end{array}$} & \multicolumn{2}{|c|}{ Toxicity } \\
\hline & $\begin{array}{c}\text { Caco-2 } \\
\text { (Log Papp } \\
\text { in } 10^{-6} \\
\mathrm{~cm} / \mathrm{s})\end{array}$ & $\begin{array}{c}\text { Intestinal } \\
\text { Absorp- } \\
\text { tion } \\
\text { (\% } \\
\text { Absorbed) }\end{array}$ & $\begin{array}{c}\text { Skin } \\
\text { Permeability } \\
(\log K p)\end{array}$ & $\begin{array}{l}\text { VDss } \\
\text { (Log } \\
\text { L/kg) }\end{array}$ & $\begin{array}{c}\text { BBB } \\
\text { Permeability } \\
\text { (Log BB) }\end{array}$ & $\begin{array}{c}\text { CNS } \\
\text { Permeability } \\
\text { (Log PS) }\end{array}$ & & $\begin{array}{c}\text { Oral } \\
\text { Rat } \\
\text { Acute Toxicity } \\
\left(\mathrm{LD}_{50}=\right. \\
\text { mol/kg) }\end{array}$ & $\begin{array}{c}\text { Oral Rat } \\
\text { Chronic } \\
\text { Toxicity } \\
\text { (LOAEL = Log } \\
\text { mg/kg_bw/day) }\end{array}$ \\
\hline 1 & 1.394 & 94.604 & -1.761 & 0.098 & 0.332 & -2.336 & 0.444 & 2.512 & 1.726 \\
\hline 2 & 1.384 & 95.015 & -2.232 & 0.159 & 0.183 & -2.599 & 0.287 & 2.674 & 1.733 \\
\hline 3 & 1.406 & 94.007 & -1.374 & 0.197 & 0.743 & -2.157 & 0.366 & 2.433 & 2.026 \\
\hline 4 & 1.397 & 92.885 & -1.652 & 0.112 & 0.437 & -2.435 & 0.347 & 2.845 & 1.728 \\
\hline 5 & 1.398 & 94.877 & -1.865 & 0.241 & 0.377 & -2.439 & 0.496 & 2.447 & 1.777 \\
\hline 6 & 1.394 & 93.326 & -2.088 & 0.148 & 0.27 & -2.644 & 0.161 & 2.956 & 1.756 \\
\hline 7 & 1.398 & 94.908 & -1.865 & 0.241 & 0.378 & -2.439 & 0.467 & 2.442 & 1.752 \\
\hline 8 & 1.403 & 92.573 & -1.449 & 0.216 & 0.767 & -2.309 & 0.446 & 2.711 & 1.857 \\
\hline 9 & 1.403 & 92.573 & -1.449 & 0.216 & 0.767 & -2.309 & 0.446 & 2.711 & 1.857 \\
\hline 10 & 1.403 & 92.097 & -1.425 & 0.225 & 0.757 & -2.309 & 0.389 & 2.75 & 1.931 \\
\hline 11 & 1.427 & 91.045 & -1.29 & 0.165 & 0.693 & -1.649 & 0.103 & 2.863 & 1.812 \\
\hline 12 & 1.406 & 90.609 & -1.552 & 0.224 & 0.759 & -2.402 & 0.336 & 3.035 & 1.843 \\
\hline 13 & 1.505 & 93.014 & -1.761 & 0.42 & 0.605 & -2.541 & 1.363 & 1.739 & 1.178 \\
\hline
\end{tabular}

1: Allyl methyl disulfide; 2: 3H-1,2-dithiole; 3: diallyl disulfide; 4: 1-propenyl-2-propenyl-(E)-disulfide; 5: allyl methyl trisulfide; 6: 3-vinyl-1,2-dithiacyclohex-4-ene; 7: 4H-1,2,3-trithiine; 8: 2-vinyl-4H-1,3-dithiine; 9: diallyl trisulfide; 10: 1-allyl-3-propyltrisulfane; 11: 5-methyl-1,2,3,4-tetrathiane; 12: diallyl tetrasulfide; 13: $\alpha$-bisabolol.

The main limitation of this study was in the development of the in vitro and in silico study to demonstrate the antioxidant capacity of the garlic EO, being very important for in vivo models, i.e., mammalian cell lines, as well as for experimental animals. However, these findings pretend to show the probable mechanism of molecular interaction of the volatile components of the EO on NADPH oxidase. In addition, there lacked a comparison of the results determined in the DPPH and $\beta$-carotene bleaching assays with other garlic EOs studied elsewhere in the world. Furthermore, there were limitations in showing the chemical profile of Peruvian garlic, which is cultivated in different lands affected by altitude, climate, and temperature, among others. Garlic EO might be a promissory antioxidant agent used in phytotherapy or in the food industry. Furthermore, the chemical structures such as $\alpha$-bisabolol and sulfur components determined in the EO could be used as templates for the design of new drugs to inhibit NADPH oxidase in the future.

\section{Conclusions}

We concluded that the essential oil of A. sativum cultivated in Peru at 2335 m.a.s.l. has a low percentage yield, and analysis with GC-MS revealed the presence of diallyl trisulfide, with $44.23 \%$, as the main volatile component of the EO, followed by 14 compounds of sulfur structures, with $55.02 \%$, and two oxygenated terpenes, namely, $\alpha$-bisabolol and one unknown constituent with the formula $\mathrm{C}_{22} \mathrm{H}_{42} \mathrm{O}_{4}$, which represent $3.75 \%$.

Regarding the antioxidant capacity in vitro, two assay methods were carried out, namely, DPPH and $\beta$-carotene bleaching assays, showing a good inhibitory capacity over other types of garlic EOs reported across the world. The presence of two compounds not detected in other garlic EOs across the world, such as $\alpha$-bisabolol (a sesquiterpene), would 
be vital in maintaining their high antioxidant power. However, garlic EO were less active than the standard antioxidants like Trolox and rutin. In the in-silico study, the activity of the phytoconstituents of the garlic EO on NADPH oxidase were studied, being $\alpha$-bisabolol the compound with the best docking score. Furthermore, this compound showed good stability during the molecular dynamics study carried out across $100 \mathrm{~ns}$, whilst diallyl trisulfide was not stable, demonstrating that those ligands with low-energy docking scores have poor stability on the target protein. Additionally, according to the ADMET prediction, all garlic components can be absorbed by oral and transdermal administration, which represent a great advantage against other compounds that experience difficulty in penetrating the gastrointestinal barrier. No toxicity was predicted, but further studies have to be developed to confirm these findings using in vivo models.

Supplementary Materials: The following are available online at https:/ / www.mdpi.com/article/10 .3390/antiox10111844/s1, Figure S1: GC chromatogram of the essential oil from garlic, Figures S2-S11: Molecular interaction studies of allyl methyl disulfide, $3 \mathrm{H}$-1,2-dithiole, diallyl disulfide, 1-propenyl 2-propenyl-(E)-disulfide, allyl methyl trisulfide, 3-vinyl-1,2-dithiacyclohex-4-ene, 2-vinyl-4H-1,3dithiine, diallyl trisulfide, 1-allyl-3-propyltrisulfane, and diallyl tetrasulfide with NADPH oxidase (PDB ID: 2CDU), surface view (left panel), and 2D (right panel) interactions.

Author Contributions: Conceptualization, O.H.-C., I.C.H.-G. and L.J.C.-R.; methodology, O.H.-C.; formal analysis, G.E.-S.B.; investigation, O.H.-C. and M.A.; writing-original draft preparation, O.H.-C.; writing-review and editing, O.H.-C. and G.E.-S.B.; funding acquisition, M.A.A. and M.A. All authors have read and agreed to the published version of the manuscript.

Funding: The authors would like to extend their sincere appreciation to Taif University Researchers Supporting Project (number TURSP-2020/309), Taif University, Taif, Saudi Arabia.

Institutional Review Board Statement: Not applicable.

Informed Consent Statement: Not applicable.

Data Availability Statement: The data is contained within the article and supplementary materials.

Acknowledgments: The authors would like to extend their sincere appreciation to Taif University Researchers Supporting Project (number TURSP-2020/309), Taif University, Taif, Saudi Arabia and the Vicerrectorado de Investigación y Desarrollo (VRID) of the Universidad Nacional San Luis Gonzaga, Ica, Peru.

Conflicts of Interest: The authors declare no conflict of interest.

\section{References}

1. Firenzuoli, F.; Jaitak, V.; Horvath, G.; Bassolé, I.H.N.; Setzer, W.N.; Gori, L. Essential Oils: New Perspectives in Human Health and Wellness. Evid. Based Complementary Altern. Med. Ecam 2014, 2014, 467363. [CrossRef]

2. Tongnuanchan, P.; Benjakul, S. Essential Oils: Extraction, Bioactivities, and Their Uses for Food Preservation. J. Food Sci. 2014, 79, R1231-R1249. [CrossRef]

3. De Lavor, É.M.; Cavalcante Fernandes, A.W.; de Andrade Teles, R.B.; Pereira Leal, A.E.B.; de Oliveira, R.G.; Gama e Silva, M.; de Oliveira, A.P.; Silva, J.C.; de Moura Fontes Araújo, M.T.; Melo Coutinho, H.D.; et al. Essential Oils and Their Major Compounds in the Treatment of Chronic Inflammation: A Review of Antioxidant Potential in Preclinical Studies and Molecular Mechanisms. Oxidative Med. Cell. Longev. 2018, 2018, 6468593. [CrossRef]

4. Palmieri, S.; Maggio, F.; Pellegrini, M.; Ricci, A.; Serio, A.; Paparella, A.; Sterzo, C. lo Effect of the Distillation Time on the Chemical Composition, Antioxidant Potential and Antimicrobial Activity of Essential Oils from Different Cannabis sativa L. Cultivars. Molecules 2021, 26, 4770. [CrossRef] [PubMed]

5. Abd-ElGawad, A.M.; Bonanomi, G.; Al-Rashed, S.A.; Elshamy, A.I. Persicaria Lapathifolia Essential Oil: Chemical Constituents, Antioxidant Activity, and Allelopathic Effect on the Weed Echinochloa Colona. Plants 2021, 10, 1798. [CrossRef]

6. Silva, J.; Abebe, W.; Sousa, S.M.; Duarte, V.G.; Machado, M.I.L.; Matos, F.J.A. Analgesic and Anti-Inflammatory Effects of Essential Oils of Eucalyptus. J. Ethnopharmacol. 2003, 89, 277-283. [CrossRef]

7. López, V.; Nielsen, B.; Solas, M.; Ramírez, M.J.; Jäger, A.K. Exploring Pharmacological Mechanisms of Lavender (Lavandula angustifolia) Essential Oil on Central Nervous System Targets. Front. Pharmacol. 2017, 8, 280. [CrossRef] [PubMed]

8. Camele, I.; Grul'ová, D.; Elshafie, H.S. Chemical Composition and Antimicrobial Properties of Mentha $\times$ Piperita Cv. 'Kristinka' Essential Oil. Plants 2021, 10, 1567. [CrossRef] 
9. Thuy, B.T.P.; My, T.T.A.; Hai, N.T.T.; Hieu, L.T.; Hoa, T.T.; Loan, H.T.P.; Triet, N.T.; van Anh, T.T.; Quy, P.T.; van Tat, P.; et al. Investigation into SARS-CoV-2 Resistance of Compounds in Garlic Essential Oil. ACS Omega 2020, 5, 8312-8320. [CrossRef] [PubMed]

10. Ayaz, M.; Sadiq, A.; Junaid, M.; Ullah, F.; Subhan, F.; Ahmed, J. Neuroprotective and Anti-Aging Potentials of Essential Oils from Aromatic and Medicinal Plants. Front. Aging Neurosci. 2017, 9, 168. [CrossRef]

11. Jung, K.-W.; Chung, M.-S.; Bai, H.-W.; Chung, B.-Y.; Lee, S. Investigation of Antifungal Mechanisms of Thymol in the Human Fungal Pathogen, Cryptococcus Neoformans. Molecules 2021, 26, 3476. [CrossRef] [PubMed]

12. Amiri, H. Antioxidant Activity of the Essential Oil and Methanolic Extract of Teucrium orientale (L.) Subsp. taylori (Boiss.) Rech. f. Iran. J. Pharm. Res. IJPR 2010, 9, 417-423.

13. Amorati, R.; Foti, M.C.; Valgimigli, L. Antioxidant Activity of Essential Oils. J. Agric. Food Chem. 2013, 61, 10835-10847. [CrossRef]

14. Ruberto, G.; Baratta, M.T. Antioxidant Activity of Selected Essential Oil Components in Two Lipid Model Systems. Food Chem. 2000, 69, 167-174. [CrossRef]

15. Farouk, A.; Mohsen, M.; Ali, H.; Shaaban, H.; Albaridi, N. Antioxidant Activity and Molecular Docking Study of Volatile Constituents from Different Aromatic Lamiaceous Plants Cultivated in Madinah Monawara, Saudi Arabia. Molecules 2021, 26, 4145. [CrossRef] [PubMed]

16. Takaishi, K.; Kinoshita, H.; Kawashima, S.; Kawahito, S. Human Vascular Smooth Muscle Function and Oxidative Stress Induced by Nadph Oxidase with the Clinical Implications. Cells 2021, 10, 1947. [CrossRef]

17. Maraldi, T. Natural Compounds as Modulators of NADPH Oxidases. Oxidative Med. Cell. Longev. 2013. [CrossRef]

18. Li, R.; Chen, W.-C.; Wang, W.-P.; Tian, W.-Y.; Zhang, X.-G. Extraction of Essential Oils from Garlic (Allium sativum) Using Ligarine as Solvent and Its Immunity Activity in Gastric Cancer Rat. Med. Chem. Res. 2010, 19, 1092-1105. [CrossRef]

19. Kodera, Y.; Kurita, M.; Nakamoto, M.; Matsutomo, T. Chemistry of Aged Garlic: Diversity of Constituents in Aged Garlic Extract and Their Production Mechanisms via the Combination of Chemical and Enzymatic Reactions (Review). Exp. Ther. Med. 2020, 19, 1574-1584. [CrossRef]

20. Yamaguchi, Y.; Kumagai, H. Characteristics, Biosynthesis, Decomposition, Metabolism and Functions of the Garlic Odour Precursor, S-Allyl-L-Cysteine Sulfoxide. Exp. Ther. Med. 2020, 19, 1528. [CrossRef] [PubMed]

21. Fernández-Sestelo, M.; Carrillo, J.M. Environmental Effects on Yield and Composition of Essential Oil in Wild Populations of Spike Lavender (Lavandula latifolia Medik.). Agriculture 2020, 10, 626. [CrossRef]

22. Khalil, N.; El-Jalel, L.; Yousif, M.; Gonaid, M. Altitude Impact on the Chemical Profile and Biological Activities of Satureja Thymbra L. Essential Oil. BMC Complementary Med. Ther. 2020, 20, 186. [CrossRef]

23. Hazrati, S.; Lotfi, K.; Govahi, M.; Ebadi, M.T. A Comparative Study: Influence of Various Drying Methods on Essential Oil Components and Biological Properties of Stachys Lavandulifolia. Food Sci. Nutr. 2021, 9, 2612-2619. [CrossRef]

24. Riego, M. De A. y El Ajo En El Contexto Mundial y Nacional; Ministerio de Agricultura y Riego: La Molina, Peru, 2020.

25. Liz Leslie Cucho-Medrano, J.; Wesley Mendoza-Beingolea, S.; Máximo Fuertes-Ruitón, C.; Elena Salazar-Salvatierra, M.; HerreraCalderon, O.; Chemical, O. Chemical Profile of the Volatile Constituents and Antimicrobial Activity of the Essential Oils from Croton Adipatus, Croton Thurifer, and Croton Collinus. Antibiotics 2021, 10, 1387. [CrossRef]

26. NIST20: Updates to the NIST Tandem and Electron Ionization Spectral Libraries I NIST. Available online: https: / / www.nist.gov / programs-projects/nist20-updates-nist-tandem-and-electron-ionization-spectral-libraries (accessed on 12 September 2021).

27. Rojas-Armas, J.P.; Arroyo-Acevedo, J.L.; Palomino-Pacheco, M.; Herrera-Calderón, O.; Ortiz-Sánchez, J.M.; Rojas-Armas, A.; Calva, J.; Castro-Luna, A.; Hilario-Vargas, J. The Essential Oil of Cymbopogon Citratus Stapt and Carvacrol: An Approach of the Antitumor Effect on 7,12-Dimethylbenz-[ $\alpha$ ]-anthracene (DMBA)-Induced Breast Cancer in Female Rats. Molecules 2020, $25,3284$. [CrossRef]

28. Tepe, B.; Sokmen, M.; Akpulat, H.A.; Sokmen, A. Screening of the Antioxidant Potentials of Six Salvia Species from Turkey. Food Chem. 2006, 95, 200-204. [CrossRef]

29. Wairata, J.; Sukandar, E.R.; Fadlan, A.; Purnomo, A.S.; Taher, M.; Ersam, T. Evaluation of the Antioxidant, Antidiabetic, and Antiplasmodial Activities of Xanthones Isolated from Garcinia Forbesii and Their In Silico Studies. Biomedicines 2021, 9, 1380. [CrossRef] [PubMed]

30. Pires, D.E.V.; Blundell, T.L.; Ascher, D.B. PkCSM: Predicting Small-Molecule Pharmacokinetic and Toxicity Properties Using Graph-Based Signatures. J. Med. Chem. 2015, 58, 4066-4072. [CrossRef]

31. Daina, A.; Michielin, O.; Zoete, V. SwissADME: A Free Web Tool to Evaluate Pharmacokinetics, Drug-Likeness and Medicinal Chemistry Friendliness of Small Molecules. Sci. Rep. 2017, 7, 1-13. [CrossRef] [PubMed]

32. Boubechiche, Z. Comparison of Volatile Compounds Profile and Antioxydant Activity of Allium Sativum Essential Oils Extracted Using Hydrodistillation, Ultrasound- Assisted and Sono-Hydrodistillation Processes. Indian J. Pharm. Educ. Res. 2017, 51, S281-S285. [CrossRef]

33. Ndoye Foe, F.M.-C.; Tchinang, T.F.K.; Nyegue, A.M.; Abdou, J.-P.; Yaya, A.J.G.; Tchinda, A.T.; Essame, J.-L.O.; Etoa, F.-X. Chemical Composition, in Vitro Antioxidant and Anti-Inflammatory Properties of Essential Oils of Four Dietary and Medicinal Plants from Cameroon. BMC Complementary Altern. Med. 2016, 16, 1-12. [CrossRef]

34. Ncir, M.; ben Ali, M.; Sellami, H.; Allagui, M.S.; Lahyani, A.; Makni Ayadi, F.; Boudawara, T.; Allouche, N.; el Feki, A.; Saoudi, M. Protective Effects of Allium Sativum Essential Oil Rich in Disulfides against Deltamethrin Induced Oxidative Stress and Hepatotoxicity in Rats. J. Food Meas. Charact. 2020, 14, 2667-2675. [CrossRef] 
35. Ashraf, S.A.; Khan, M.A.; Awadelkareem, A.M.; Tajuddin, S.; Ahmad, M.F.; Hussain, T. GC-MS Analysis of Commercially Available Allium Sativum and Trigonella Foenum-Graecum Essential Oils and Their Antimicrobial Activities. J. Pure Appl. Microbiol. 2019, 13, 2545-2552. [CrossRef]

36. Torpol, K.; Wiriyacharee, P.; Sriwattana, S.; Sangsuwan, J.; Prinyawiwatkul, W. Antimicrobia Activity of Garlic (Allium sativum L.) and Holy Basil (Ocimum sanctum L.) Essential Oils Applied by Liquid vs. Vapour Phases. Int. J. Food Sci. Technol. 2018, 53, 2119-2128. [CrossRef]

37. Dziri, S.; Casabianca, H.; Hanchi, B.; Hosni, K. Composition of Garlic Essential Oil (Allium Sativum L.) as Influenced by Drying Method. J. Essent. Oil Res. 2014, 26, 91-96. [CrossRef]

38. Delazar, A.; Bahmani, M.; Shoar, H.H.; Tabatabaei-Raisi, A.; Asnaashari, S.; Nahar, L.; Sarker, S.D. Effect of Altitude, Temperature and Soil on Essential Oil Production in Thymus Fedtschenkoi Flowers in Osko and Surrounding Areas in Iran. J. Essent. Oil Bear. Plants 2013, 14, 23-29. [CrossRef]

39. Lawrence, R.; Lawrence, K. Antioxidant Activity of Garlic Essential Oil (Allium Sativum) Grown in North Indian Plains. Asian Pac. J. Trop. Biomed. 2011, 1, S51-S54. [CrossRef]

40. Mnayer, D.; Fabiano-Tixier, A.-S.; Petitcolas, E.; Hamieh, T.; Nehme, N.; Ferrant, C.; Fernandez, X.; Chemat, F. Chemical Composition, Antibacterial and Antioxidant Activities of Six Essentials Oils from the Alliaceae Family. Molecules 2014, $19,20034$. [CrossRef]

41. Bajpai, V.K.; Sharma, A.; Kim, S.H.; Baek, K.-H. Chemical Composition, Antioxidant, Lipid Peroxidation Inhibition and Free Radical Scavenging Activities of Microwave Extracted Essential Oil from Allium Sativum. J. Essent. Oil Bear. Plants 2015, 18, 300-313. [CrossRef]

42. Chen, C.; Cai, J.; Liu, S.; Qiu, G.; Wu, X.; Zhang, W.; Chen, C.; Qi, W.; Wu, Y.; Liu, Z. Comparative Study on the Composition of Four Different Varieties of Garlic. PeerJ 2019, 7, e6442. [CrossRef] [PubMed]

43. Schepetkin, I.A.; Kirpotina, L.N.; Khlebnikov, A.I.; Balasubramanian, N.; Quinn, M.T. Neutrophil Immunomodulatory Activity of Natural Organosulfur Compounds. Molecules 2019, 24, 1809. [CrossRef] [PubMed]

44. Colín-González, A.L.; Santana, R.A.; Silva-Islas, C.A.; Chánez-Cárdenas, M.E.; Santamaría, A.; Maldonado, P.D. The Antioxidant Mechanisms Underlying the Aged Garlic Extract- and S-Allylcysteine-Induced Protection. Oxidative Med. Cell. Longev. 2012, 2012, 907162. [CrossRef] [PubMed]

45. Martínez, L. Automatic Identification of Mobile and Rigid Substructures in Molecular Dynamics Simulations and Fractional Structural Fluctuation Analysis. PLoS ONE 2015, 10, e0119264. [CrossRef] [PubMed]

46. Horky, P.; Skalickova, S.; Smerkova, K.; Skladanka, J. Essential Oils as a Feed Additives: Pharmacokinetics and Potential Toxicity in Monogastric Animals. Animals 2019, 9, 352. [CrossRef] [PubMed] 